\title{
A representação do outro: as modificações na concepção do "estrangeiro", no imaginário dos estudantes universitários transnacionais da Tríplice Fronteira. ${ }^{1}$
}

\author{
La representación del otro: las modificaciones en la concepción del \\ "extranjero", en el imaginario de los estudiantes universitarios \\ transnacionales de la Triple Frontera.
}

\author{
The representation of the other: the modifications in the conception of the \\ "foreigner", in the imaginary of the transnational university students of the \\ Triple Frontier.
}

\author{
Suzana Angela Biesdorf ${ }^{2}$
}

\begin{abstract}
Resumo
Ocorreu, nas últimas décadas, um boom universitário, na região da tríplice fronteira entre Argentina, Brasil e Paraguai. No presente artigo, pretendo estudar o impacto da convivência cultural nos estudantes universitários fronteiriços desta região. Os mesmos se deslocam cotidianamente entre os países onde vivem e onde estudam, na denominada região da Tríplice Fronteira. Pretendo, deste modo, verificar como se dão as mudanças na representação do "outro", a partir da vivência transitória desses estudantes em outro país. No que se refere ao desenho da pesquisa, preliminarmente, farei uma breve dissertação sobre os conceitos de fronteiras e ambientes fronteiriços. Na sequência, uma sucinta análise acerca da utilização da expressão "Tríplice Fronteira" para denominação da zona geopolítica em questão. Ainda, abordarei o processo de interação cultural e linguística no território em análise. Por fim, entrevistarei estudantes, dos três países, no intuito de proceder à análise proposta. Pude verificar nesta pesquisa que cruzar a fronteira, para estudar uma carreira universitária, não implica apenas na aquisição de conhecimento formal e técnico. Há significativa troca de experiências, com o compartilhamento de costumes e formas de comunicação. Também houve drástica mudança de concepção, para melhor, sobre o "outro", ou seja, acerca do país vizinho e das pessoas que o habitam.
\end{abstract}

Palavras-Chave: Fronteira; Ambiente fronteiriço; Estudantes universitários; Interação linguística e cultural; Representação do outro.

\section{Resumen}

Se ha producido en las últimas décadas un boom universitario, en la región de la triple frontera entre Argentina, Brasil y Paraguay. En el presente artículo, pretendo estudiar el impacto de la convivencia cultural en los estudiantes universitarios fronterizos de esta región. Los mismos se desplazan cotidianamente entre los países donde viven y donde estudian, en la denominada región de la Triple Frontera. Por lo tanto, deseo comprobar cómo se dan los cambios en la representación del "otro", a partir de la vivencia transitoria de esos estudiantes en otro país. En lo que se refiere al diseño de la investigación, preliminarmente, haré una breve disertación sobre los conceptos de fronteras y ambientes fronterizos. A continuación, un breve análisis sobre la utilización de la expresión «triple frontera» para la denominación de la zona geopolítica en cuestión. A continuación, abordaré el

\footnotetext{
${ }^{1}$ Artigo apresentado no Simpósio Temático - Diálogos interculturais de fronteiras: perspectivas teóricas e experiências compartilhadas, durante o II Seminário Latino-Americano de Estudos em Cultura - SEMLACult em Foz do Iguaçu/PR, Brasil, 2018.

${ }^{2}$ Mestranda no Programa de Pós-Graduação Interdisciplinar em Estudos Latino-Americanos; UNILA; Foz do Iguaçu, Paraná, Brasil; suzana.biesdorf@unila.edu.br.
} 
proceso de interacción cultural y lingüística en el territorio en análisis. Por último, entrevistaré a estudiantes de los tres países con el fin de proceder al análisis propuesto. Pude comprobar en esta investigación que cruzar la frontera para estudiar una carrera universitaria no implica sólo la adquisición de conocimiento formal y técnico. Hay un significativo intercambio de experiencias, con el intercambio de costumbres y formas de comunicación. También hubo un drástico cambio de concepción, para mejor, sobre el "otro", o sea, acerca del país vecino y de las personas que lo habitan.

Palabras clave: Frontera; Medio Ambiente Fronterizo; Estudiantes Universitarios; Interacción lingüística y cultural; Representación del outro.

\begin{abstract}
In the last decades, there has been a university boom in the region of the triple border between Argentina, Brazil and Paraguay. In this article, I intend to study the impact of cultural coexistence on the border university students of this region. They travel daily between the countries where they live and study in the so-called Triple Frontier region. I intend, therefore, to verify how the changes in the representation of the "other" take place, from the transitory experience of these students in another country. As far as the research design is concerned, I will first make a brief dissertation on the concepts of frontiers and border environments. This is followed by a brief analysis on the use of the term "Triple Border" to designate the geopolitical zone in question. Still, I will approach the process of cultural and linguistic interaction in the territory under analysis. Finally, I will interview students from all three countries in order to carry out the proposed analysis. I could verify in this research that crossing the border to study a university career does not only involve the acquisition of formal and technical knowledge. There is a significant exchange of experiences, with the sharing of customs and forms of communication. There has also been a drastic change in conception, for the better, about the "other," that is, about the neighboring country and the people who inhabit it.
\end{abstract}

Keywords: Border; Frontier environment; University students; Linguistic and cultural interaction; Representation of the other.

\title{
1. Introdução
}

Nas duas últimas décadas, ocorreu um boom universitário na região da Tríplice Fronteira entre Argentina, Brasil e Paraguai, especialmente nas cidades de Foz do Iguaçu e Ciudad del Este.

Em Foz do Iguaçu, o crescimento do polo universitário ocorreu a partir de um contexto nacional de forte expansão e interiorização do ensino superior privado, com incentivo governamental, a partir de políticas públicas de bolsas integrais e parciais para alunos carentes (PROUNI) e de financiamento subsidiado (FIES).

No tocante às universidades públicas brasileiras, houve um expressivo aumento na oferta de cursos na UNIOESTE (universidade pública estadual), bem como a criação, em 2010, da UNILA (universidade federal de integração latino-americana).

No lado paraguaio, Ciudad del Este, foi criada em 1993 a UNE (Universidad Nacional del Este), objetivando a interiorização do ensino universitário público no país, até então restrito à região metropolitana da capital paraguaia, Assunção.

Houve também um forte crescimento do ensino privado, com a implantação, na região, da Universidad Privada del Este - UPE, da Universidad Politécnica y Artística del Paraguay UPAP, dentre outras. 
O forte crescimento da demanda por essas universidades privadas paraguaias também decorreu do exponencial crescimento do número de alunos brasileiros nos cursos de Medicina.

Na cidade de Puerto Iguazu, no lado argentino da fronteira, existem polos de atendimento das faculdades de Misiones e Buenos Aires, dentre outras.

Os estudantes a serem entrevistados para o presente estudo serão os brasileiros que estudam no Paraguai, em Ciudad del Este, e que frequentam, principalmente, o curso de Medicina; os paraguaios e argentinos que vêm para Foz do Iguaçu, no Brasil, em busca de acesso à universidade pública gratuita (Universidade Federal da Integração Latino-Americana UNILA); bem como eventuais brasileiros e paraguaios que estudem em Puerto Iguazu, na Argentina.

Utilizando tal ferramenta (entrevistas), pretendo verificar como se dão as mudanças na representação do "outro", a partir da vivência transitória dos estudantes universitários fronteiriços em outro país.

Além disso, também analisarei o impacto da convivência cultural e linguística, nesses estudantes, durante sua trajetória universitária.

\section{Métodos}

Para SILVA et al. (2005), o contexto das interações sociais é formado por diversos conceitos e significados, que são socialmente construídos. O que busco neste estudo é exatamente uma análise interpretativa dos significados das relações sociais entre sujeitos de diferentes origens culturais, que convivem no contexto universitário da Tríplice Fronteira. Diante do objetivo proposto, o presente estudo será delineado no método qualitativo.

A pesquisa será de cunho descritivo, posto que a mesma analisa, observa, registra e correlaciona aspectos que envolvem fatos ou fenômenos, sem manipulá-los.

Será feito um levantamento bibliográfico no intuito de relacionar o estudo com as teorias sobre fronteiras, culturas, interação cultural e linguística, a fim de embasar as hipóteses levantadas e os resultados alcançados.

A coleta de dados desta pesquisa se dará através da pesquisa bibliográfica e do estudo de campo. Na pesquisa de campo serão entrevistados estudantes que se deslocam cotidianamente entre os países nos quais vivem e naqueles em que estudam, na Tríplice Fronteira. A ferramenta utilizada será um questionário veiculado on line (redes sociais, correios eletrônicos, etc.) para estudantes brasileiros, paraguaios e argentinos da região.

\section{Sobre as Fronteiras}


Segundo Apadurai (1999), vivemos um momento paradoxal, no qual coexistem simultaneamente um recrudescimento do nacionalismo e um declínio do Estado-Nação moderno (entendido como organização compacta e isomórfica de território, ethnos e aparelho governamental).

Nos países integrantes do Mercosul, o processo de integração não se processou com a mesma intensidade do que na União Europeia (livre trânsito de pessoas e mercadorias). No entanto, a despeito da ausência de consenso entre os governos dos países desse bloco latinoamericano, no sentido de um aumento maior de integração, as pessoas e empresas têm intensificado o nível de cooperação entre as citadas nações.

Para Paasi (1999), as fronteiras são tanto símbolos quanto instituições que produzem, simultaneamente, distinções entre grupos sociais, e são produzidas por eles. Elas separam grupos e comunidades sociais, mas também mediam contatos entre eles. As fronteiras fornecem padrões normativos que regulam e direcionam as interações entre membros de grupos sociais, regras sobre como cruzar fronteiras e regras que governam a troca entre as pessoas, bens e mensagens simbólicas.

Como símbolos, elas são meios e instrumentos de controle social e comunicação e construção de significados e identidades. Como instituições, conectam o passado, o presente e o futuro, ou seja, elas constroem uma continuidade para interação social.

Para Martinez (1994), infinitas variações hão de se esperar no meio fronteiriço por conta das divergências na interação fronteiriça, em função da heterogeneidade, tamanho das nações, relação política, níveis de crescimento, configuração étnica, cultural e linguística.

\subsection{O ambiente da fronteira}

As região fronteiriças são loci que possuem, em regra, características não encontradas em nas regiões centrais dos países. São nestas regiões em que ocorrem, mais intensamente, as interações transnacionais, tanto as de natureza econômica quanto aquelas de caráter político e cultural.

Os conflitos de natureza bélica se iniciam nestas regiões; a acomodação dos mesmos também se dá nos polos fronteiriços.

De acordo com Martinez (1994) existem quatro tipos de interação fronteiriça: a) alienadas; b) coexistentes; c) interdependentes; d) integradas.

Nas fronteiras alienadas existe pouca ou quase nenhuma interação. Esta alienação é causada por guerras, disputas políticas, nacionalismo extremado, animosidade ideológica, inimizade religiosa, divergências culturais e rivalidade étnica, ainda, um controles rígidos 
sobre os tráfegos fronteiriços. Um exemplo atual é a fronteira entre a Coreia do Norte e Coreia do Sul.

Nas fronteiras coexistentes, existem conflitos que, no entanto, são gerenciáveis. O modelo coexistente também ocorre quando as condições desfavoráveis internas, em um ou outro país, impedem cooperação binacional.

Em ambos os casos, existe um gerenciamento de crise que permite a manutenção de um padrão mínimo de estabilidade de relacionamento. Um exemplo contemporâneo deste tipo de fronteira é a de Israel e Egito.

No modelo de fronteiras interdependentes, a região fronteiriça é simbioticamente conectada com a outra. Isso é possível através de relações internacionais estáveis e a existência de um ambiente econômico favorável. Há mútuo benefício econômico e troca paritária.

A interdependência econômica cria muitas oportunidades para as fronteiras estabelecerem relações sociais além da barreira, o que permite significante intercâmbio cultural.

O sistema econômico gera um sistema social e cultural binacional. No entanto, há casos de fronteiras interdependentes nas quais há uma assimetria entre os parceiros binacionais. Nestes casos, uma nação é mais forte que a outra e, consequentemente, é dominadora. O país mais rico extrai matéria prima e mão-de-obra barata do lado mais pobre. Um modelo a ser citado é o da fronteira entre Estados Unidos e México.

Já no caso das fronteiras integradas, há a eliminação das principais diferenças políticas e barreiras comerciais. Não há restrições no que se refere à mobilidade humana.

O nacionalismo dá lugar a um novo internacionalismo que enfatiza a paz, relações e melhorias na qualidade de vida para as nações através do comércio e da tecnologia.

As duas nações, no mesmo nível de desenvolvimento, convivem integradamente. No entanto, para que isso ocorra, as mesmas precisam estar simétricas: políticas estáveis, segurança militar e economicamente fortes.

Como exemplo, Bélgica e sua vizinhança; região basiliensis (Suíça, França e Alemanha) são pioneiras nas novas formas de cooperação e planejamento internacional.

A seguir, analisarei a Tríplice Fronteira, que é o ambiente deste estudo.

\subsection{A Tríplice Fronteira em tela}

A região da Tríplice Fronteira foi inicialmente colonizada por exploradores de madeira, erva mate e outros produtos de natureza extrativista. Outro fator inicial no processo 
colonizatório foi a instalação das Forças Armadas, nos três países, em razão da demarcação e controle dos territórios dos respectivos países.

A explosão populacional na região ocorreu a meados da década de 1970, com a assinatura do tratado de Itaipu, entre Brasil e Paraguai, e a vinda de milhares de trabalhadores, de todo o Brasil, para a instalação da usina hidrelétrica.

Simultaneamente, neste período ocorreu um grande aumento do comércio binacional entre Brasil e Paraguai, tanto com a implantação de empresas exportadoras do lado brasileiro, nos bairros adjacentes à Ponte da Amizade (Vila Portes e Jardim Jupira, em Foz do Iguaçu) quanto no lado paraguaio.

No final da década de 1980 e início da década de 1990, ocorreram dois fenômenos socioeconômicos, simultaneamente: a forte redução na utilização de mão-de-obra pela Itaipu Binacional e a explosão do "comprismo", que se caracterizou pela prática de contrabando e descaminho, por pessoas excluídas do mercado de trabalho formal.

Na referida década de 1990, em função do aumento do narcotráfico, da prática de assaltos contra os "compristas" e do roubo de veículos brasileiros com destino para o Paraguai, ocorreu um intenso incremento dos índices de crimes violentos na região, relacionados com os conflitos entre diversos grupos criminosos que controlavam as rotas e territórios do tráfico, bem como os portos clandestinos, em ambos os lados da fronteira, utilizados para a passagem de mercadorias contrabandeadas, armas, drogas, cigarros e munição.

Em relação a denominação desta região, integrada pelas cidades de Puerto Iguazú (Argentina), Ciudad del Este (Paraguai) e Foz do Iguaçu (Brasil), como Tríplice Fronteira, Montenegro (2007), informa que tal denominação passou a ser utilizada a partir da suspeita de terroristas islâmicos na região, após os atentados na embaixada de Israel na Argentina, em 1992. A oficialização do nome de Tríplice Fronteira se deu em 1998, após a assinatura, pelos governos dos três países, de um plano de segurança para a região.

A mesma autora reforça que a instituição Tríplice Fronteira se conforma, portanto, como uma entidade cuja existência transcende os limites jurídicos entres os respectivos países.

Menciona que, especialmente a partir do ataque às torres gêmeas, nos EUA, em 11 de setembro de 2001, a mídia passa a reforçar a ideia de que a região é uma "zona cinzenta", uma espécie de território sem lei, que escapa ao controle do poder estatal.

A referida pesquisadora ainda cita que, especialmente após o crescimento acelerado dos últimos quarenta anos, o espaço se tornou uma região transnacional, com intensa 
circulação de pessoas, bens e significados. Cita, ademais, que este locus possui grande diversidade cultural, em razão do grande número de imigrantes árabes, chineses, coreanos, dentre outros.

Consequentemente, podemos concluir que a referida Tríplice Fronteira se enquadra, a partir do modelo exposto no tópico anterior, proposto por Martinez (1994), na categoria de fronteira interdependente.

Todavia, as relações entre os diversos países não é exatamente simétrica. No lado paraguaio, em Ciudad del Este, há uma forte presença de empresas e empresários brasileiros, especialmente em ramos de atividade cuja origem das mercadorias é o Brasil, tais como autopeças, equipamentos agrícolas, ferramentas e concessionárias de veículos.

Em Foz do Iguaçu, é pequena a presença de empresas paraguaias e argentinas. A cidade, no entanto, fornece grande parte dos produtos hortifrutigranjeiros consumidos na cidade-gêmea paraguaia. Os comércios dos ramos de confecções, calçados, gastronômico, dentre outros, também são fortemente frequentados tanto por argentinos quanto por paraguaios.

Há, ainda, significativa presença de vendedores ambulantes paraguaios, no lado brasileiro da fronteira, que comercializam diversos produtos (alho, frutas, além de diversas mercadorias oriundas do Paraguai).

Em Puerto Iguazu, é forte a presença brasileira relacionada ao turismo, com intenso fluxo de vans, táxis e veículos particulares, com destino às Cataratas argentinas e aos bares, restaurantes e à feira livre da cidade.

Há, portanto, um intenso trânsito de pessoas, mercadorias e serviços. Assim sendo, também há relevante interação cultural e linguística entre os povos.

\subsection{A interação cultural na região}

De acordo com Febvre in Kuper (2002), (1930, apud Eliot, 1939), (...) "uma cultura é mais do que a reunião de artes, costumes e crenças religiosas. Todas essas coisas agem entre si, e para compreender verdadeiramente uma é preciso compreender todas". O mesmo autor sumariza que "cultura inclui todas as atividades e interesses característicos de um povo".

Geertz (1997), citando Max Weber, que afirma que o homem é um animal amarrado a teias de significados que ele mesmo teceu, defende que a análise cultural não é uma ciência experimental em busca de leis, mas uma ciência interpretativa, à procura do significado.

Entre as especificidades da fronteira, ainda se fala de uma construção de identidade do povo fronteiriço. Para Paasi (1999) as identidades são produzidas através das fronteiras e elas 
se tornam parte de identidades coletivas, memórias compartilhadas e senso de continuidade entre gerações.

As identidades são frequentemente representadas em termos de uma diferença entre Nós e os Outros, em vez de ser algo intrínseco a um determinado grupo de pessoas. Apesar do conceito de identidade ser baseado na diferenciação, isto não significa uma inevitável animosidade em relação ao Outro.

Dou início a este tópico sublinhando que os destinos do forte processo imigratório na Tríplice Fronteira foram principalmente as cidades de Foz do Iguaçu, no Brasil e Ciudad del Este, no Paraguai.

A construção da barragem de Itaipu se deu a partir de um acordo binacional entre os referidos países, que acarretou na vinda de milhares de trabalhadores de ambos os países para a construção da usina; o fenômeno do "comprismo" também teve como principais polos o Brasil, como destino e o Paraguai, como origem das mercadorias.

Ainda, analisando não apenas a economia das fronteiras, ressalto que a forte presença brasileira no setor do agronegócio paraguaio também redundou em um aumento das populações e da atividade econômica de Foz do Iguaçu e Ciudad del Este.

Assim, há uma enorme discrepância entre as populações de Foz do Iguaçu (264.044 habitantes - IBGE/2017) e Ciudad del Este (299.255 habitantes - DGEEC/2015) com Puerto Iguazu (82.849 habitantes - INDEC/2010).

Houve também um significativo processo imigratório, nas cidades brasileira e paraguaia, que envolveu a vinda de milhares de pessoas do Oriente Médio (Palestina, Líbano e Síria, dentre outros países), criando o segundo maior contingente populacional árabedescendente do Brasil, na cidade de Foz do Iguaçu.

Com a chegada desta colônia, ocorreu a instalação de duas mesquitas e duas escolas árabes, na cidade brasileira. A atividade principal desta população é a de natureza comercial.

Nessas cidades também ocorreu um significativo aumento das populações oriundas do Extremo Oriente, majoritariamente de chineses étnicos (Taiwan) e de coreanos, cuja atividade predominante também é o comercio.

Também habitam a região as populações indígenas que, por falta de políticas públicas efetivas, vivem sob condição precária.

Silva (2008) relata que, diferentemente das condições do imigrante argelino na França, estudadas por Sayad (1998), onde o imigrante será sempre imigrante e estrangeiro, o esforço do poder público, na cidade de Foz do Iguaçu, parece ser o de constituir o imigrante na condição de cidadão. 
Ainda, a autora informa que o governo do município de Foz do Iguaçu criou uma logomarca para a cidade: "Foz, a cidade de todos nós". Segundo a mesma: "Esse emblema também parece expressar o reconhecimento público de um elemento marcante da formação da sua estrutura urbana, constituída pela história da chegada de sucessivos grupos, nacionais e estrangeiros, que emigraram em busca de oportunidades e de outras inúmeras razões."

A marcante presença histórica de diversos fluxos migratórios, com distintas origens, parece efetivamente ter criado, na região, um ambiente no qual há maior diversidade cultural do que em outras cidades do mesmo porte, nas regiões mais centrais dos respectivos países, em que, normalmente, há maior homogeneidade no processo colonizatório.

É certo que as diversas comunidades étnicas ainda possuem espaços próprios, onde compartilham seus valores e crenças, culturais e religiosas.

Todavia, é inegável que os elementos oriundos das diversas culturas passaram a ser "apropriados" pela cultura típica da região e, de certa forma, foram resinificados como elementos de uma nova cultura.

Deste modo, o narguilé, de origem árabe, é um elemento presente em múltiplas rodas de conversas entre os jovens da fronteira, mesmo naquelas formadas por pessoas sem qualquer descendência árabe.

O mate ou o tereré também podem ser vistos numa roda de conversa entre um nordestino, que estuda medicina no Paraguai, um jovem comerciante de descendência chinesa e um argentino, que estuda em uma universidade pública brasileira.

Apesar dos diversos grupos ainda não se encontram em um processo pleno, completo, de integração, é inegável que as teias de relações e significados construídas na região criaram um caldo de cultura próprio da região que, sem dúvida, pode ser denominada de cultura da Tríplice Fronteira.

\subsection{A interação linguística na Tríplice Fronteira}

No que se refere ao aspecto linguístico, as principais interações são entre as populações de fala hispânica e aquelas de língua portuguesa. Cumpre ainda citar a forte presença do guarani, idioma da população nativa indígena, que também é idioma oficial do Paraguai.

A população local denomina de "portunhol" a mescla de palavras utilizadas na interações entre estas populações.

Segundo Bonfim (2012), o portunhol da fronteira não se confunde com as alusões jocosas utilizadas por publicitários, que se referem meramente ao uso de duas ou três 
interjeições em espanhol, na peça publicitária, visando dar efeito cômico à mesma. Tampouco se refere ao que a linguística denomina de interlíngua, que seria "a linguagem produzida por um falante não nativo a partir do início do aprendizado, caracterizada pela interferência da língua materna (...)"3.

Trata-se de um fenômeno linguístico que permeia a grande fronteira entre o Brasil e os países que o circundam, nos mais de $16.000 \mathrm{~km}$ de fronteira, que se molda a partir da necessidade de comunicação, nas trocas econômicas e culturais desenvolvidas em tais regiões.

No caso da fronteira Brasil/Paraguai, Diegues (2005), citado por Bonfim (2012) denominou a interação linguística de "portuñol selvaje": "U portunhol salvaje es la língua falada em la frontera du Brasil com u Paraguai por la gente simples que increíblemente sobrevive de teimosia, brisa, amor al imposible, mandioca, vento y carne de vaca."

Todavia, as interações linguísticas na fronteira não se limitam ao português, espanhol e guarani. A supramencionada diversidade étnica da região faz com que, estejam presentes nas conversas do cotidiano o árabe, o mandarim e o coreano.

A criação da Universidade Federal de Integração Latino-Americana (UNILA), no município de Foz do Iguaçu, bem como o recente fenômeno imigratório haitiano para o Brasil, implicaram na presença, na região, de novos sons e fonemas, como a presença do créole.

O intenso fluxo turístico mundial, em razão da existência das Cataratas do Iguaçu e da usina da Itaipu, tornam usual a presença do inglês, francês, alemão, italiano e japonês na cidade.

Por óbvio, o alcance e a penetração recíproca destes idiomas, neste meio fronteiriço, depende vários fatores.

O primeiro fator citado por Day (2013) é a distância de poder. Segundo a autora, tal conceito "está diretamente vinculada à relação de motivos que um indivíduo possui para aprender e para utilizar uma determinada língua."

Neste sentido, cumpre frisar que os idiomas preponderantes no setor turístico da cidade são o inglês e o espanhol, sendo que a utilização do primeiro está intimamente vinculada à hegemonia norte-americana no cenário econômico e político mundial do pósguerra.

\footnotetext{
${ }^{3}$ Interferência, Interlíngua e Fossilização. Ricardo Schütz. Atualizado em 1 de julho de 2006. Disponível em: http://www.sk.com.br/sk-interfoss.html; acesso em 06/06/2018.
} 
Ainda no que se refere à correlação entre língua e poder, parece-me impressionante a resistência do idioma nativo do povo guarani, na população paraguaia, em face do agressivo processo colonizatório espanhol na América Latina.

No Brasil, por exemplo, a resiliência do tupi-guarani e das demais línguas nativas, no conjunto da população não-nativa, se restringiu exclusivamente a nomes de rios, cidades e ruas.

A penetração recíproca entre o espanhol e o português na região é facilitada por dois outros fatores, denominados pela pesquisadora supramencionada de distância geográfica e distância interlinguística.

A extensa fronteira entre o Brasil e os países hispano-falantes da América do Sul criam um ambiente propício para que os sons e fonemas da língua não-nativa, do país contíguo, sejam familiares, especialmente nas regiões mais próximas aos limites fronteiriços.

Da mesma forma, a raiz comum latina de ambos os idiomas faz com que exista uma pequena distância interlinguística entre os mesmos, facilitando o aprendizado.

É possível concluir, consequentemente, que a região é um ambiente rico para o estudo das interações interlinguísticas, face à variedade de fatores que interagem na comunicação interpessoal da Tríplice Fronteira.

\section{Análise dos dados}

A pesquisa de campo se deu por meio de aplicação de questionário on line, com a utilização de um formulário com questões abertas, no Google Drive. O período de disponibilização do mesmo foi de vinte dias.

Na coleta dos dados foi possível ter acesso às amostras de estudantes dos três países vizinhos, Argentina, Brasil e Paraguai, totalizando vinte entrevistados.

No que tange à nacionalidade, nove estudantes se declararam brasileiros, sete paraguaios e quatro argentinos. Onze estudam ou estudaram no Brasil, sete no Paraguai e dois na Argentina.

Quanto à faixa-etária, dez estudantes declararam ter entre 17 a 22 anos; cinco entre 23 a 29 anos e cinco acima de 30 anos. No tocante ao gênero, treze estudantes se declararam do gênero feminino e sete do gênero masculino.

Em relação ao tempo em que estudam ou estudaram no país vizinho, cinco estudantes estudam há menos de 1 ano, cinco entre 1 a 2 anos; oito entre 2 a 3 anos e dois há mais que 3 anos. 
A maioria dos entrevistados (nove) é brasileira (45\%); sendo que, destes, sete estudam no Paraguai e apenas dois na Argentina. Trinta e cinco por cento dos entrevistados se declararam paraguaios; todos estudam no Brasil. Por fim, quatro estudantes (20\%) se declaram argentinos, sendo que todos também estudam no Brasil.

Quando suscito o motivo pelo qual eles estudam fora de seu país, surgiram as seguintes respostas: dez estudantes (50\%) declinaram questões econômicas (mensalidade menor e bolsa de intercâmbio); três estudantes (15\%) apontaram o projeto UNILA, no Brasil, como fator decisivo; três estudantes (15\%) informaram que buscaram estudar fora do país visando uma melhor qualidade de educação; dois estudantes (10\%) mencionaram o interesse em estudar no exterior, simplesmente; um estudante (5\%) sinalizou o interesse específico na carreira de medicina da UNILA e um estudante (5\%) disse que há falta de reconhecimento profissional em seu país.

Dos dez estudantes que apontaram o fator econômico como elemento decisivo para buscar estudos universitários fora do país, seis deles são brasileiros que estudam Medicina no Paraguai.

Na sequência perguntei sobre o que lhes atraía no país antes de estudar nele. As respostas foram as seguintes: sete estudantes (35\%) indicaram o comércio; quatro estudantes (20\%) indicaram aspectos culturais e linguísticos; três estudantes (15\%) mencionaram que quiseram estudar em uma cidade diferente da que vivem; dois (10\%) citaram a segurança; um estudante (5\%) indicou o turismo como fator prévio de interesse; um (5\%) mencionou ver melhor opção de educação e dois (10\%) não responderam;

Dos sete estudantes que indicaram a questão comercial como ponto de atração inicial no país antes de estudar nele, cinco são brasileiros que foram estudar no Paraguai.

Em relação ao que não lhes parecia interessante no país antes de estudar nele verifico que: nove estudantes (45\%) levantaram questões linguísticas e culturais; três entrevistados (15\%) apontaram questões sociopolíticas, tais como o atraso no desenvolvimento e a corrupção; um estudante (5\%) indicou a mercantilização da religião; um estudante (5\%) informou a baixa qualidade do estudo; um estudante (5\%) menciona questão de segurança; outro (5\%) a desorganização e quatro dos entrevistados (20\%) não responderam/não informaram;

O próximo questionamento foi o seguinte: O que vê de melhor hoje no país vizinho em que estuda? Nove estudantes (45\%) indicaram fatores culturais, tais como hospitalidade, receptividade e amabilidade; cinco (25\%) apontaram fatores logísticos e de organização do 
país, tais como transportes; quatro (20\%) sinalizaram a possibilidade de uma educação melhor; dois (10\%) não responderam.

Em contraponto ao que foi perguntado acima, o foco da pergunta seguinte foi o questionamento acerca do que os entrevistados veem de negativo hoje sobre o país vizinho em que estudam. Sete dos entrevistados (35\%) mencionaram questões políticas, tais como corrupção, governo Temer (Brasil) e Macri (Argentina); três (15\%) avaliaram negativamente os quesitos de segurança, infraestrutura e organização; três (15\%) viram a pobreza como fator negativo; dois (10\%) disseram que não viram nada de negativo; dois (10\%) levantaram as questões de preconceito com estrangeiros, conservadorismo religioso e tendência pró-militar e três pessoas $(15 \%)$ não responderam.

No seguinte módulo de questões, perguntei sobre as pessoas do país vizinhos, se já as conheciam, como as viam e como as veem atualmente. Doze deles (60\%) já conheciam pessoas do país no qual foram estudar os outros não (40\%).

Solicitei que, usando poucos adjetivos, dissessem o que era o(a) "paraguaio(a)", "brasileiro(a)" ou "argentino(a)" antes deste contato mais intenso. As respostas foram as seguintes: doze dos entrevistados $(60 \%)$ levantaram questões negativas; sete estudantes $(35 \%)$ suscitaram questões de ordem positiva e um aluno (5\%) não respondeu.

Logo na sequência questionei sobre como passaram a ver essas pessoas após começarem a estudar no país.

Dezoito (90\%) das respostas levantaram fatores de ordem positiva e somente dois (10\%) entrevistados mantiveram suas opiniões negativas sobre os nativos do país vizinho.

No próximo bloco de questões levantei questões de ordem cultural e linguística, no intuito de verificar as influências destes fatores na comunicação e vivência destes estudantes. Perguntei, à princípio, qual idioma usam para se comunicar no país que estuda.

Assim, dos entrevistados dez (50\%) responderam que utilizam tanto o idioma nativo quanto o do país em que estudam; sete (35\%) disseram que utilizam somente o idioma do país em que estudam; dois estudantes (10\%) que usam somente o seu idioma nativo e um estudante (5\%) mencionou o Portunhol como forma de comunicação.

Ainda perguntei a eles se, quando retornam para suas casas, as pessoas da sua família mencionam alguma modificação em relação ao seu comportamento ou fala.

Doze entrevistados $(60 \%)$ responderam que não e oito $(40 \%)$ disseram que sim. Dos que responderam afirmativamente, as alterações percebidas pela família se referem a fatores linguísticos (utilização do idioma estrangeiro em casa) e alimentares (incorporação de comidas típicas do outro país). 
A fim de complementar a questão acima, também questionei se existe algum costume do país que estuda ou estudou (hábito alimentar, musical, vestimenta, dentre outros) que tenha incorporado no seu dia-a-dia e quais seriam.

Doze estudantes $(60 \%)$ responderam que sim e oito $(40 \%)$ responderam que não. Eles mencionaram fatores culturais, tais como a música, a vestimenta e a alimentação (tereré).

Por fim, em relação à questão linguística questionei se existem palavras da língua do país em que estudam que foram incorporados a seu vocabulário diário e quais seriam.

Neste quesito a resposta positiva foi bem preponderante, posto que dezesseis $(80 \%)$ entrevistados afirmam que sim e apenas (20\%) dizem não. Os exemplos citados foram muitos, desde gírias, saudações e interjeições.

Finalizando o questionário, solicitei que adicionassem comentários que considerassem válidos para complementar a pesquisa, os quais transcrevo abaixo:

"Muy consciso el cuestionario"; "Estudar no país vizinho me gerava muito preconceito e percebi que minha ignorância me limitou a buscar esse sonho mais cedo"; "La inquietud de cualquier extranjero es la de que los brasileros son egoístas en el sentido de que no quieren hablar el español"; "Muito obrigada Paraguai"; "Estudar fora do seu país não é fácil, são vários fatores que envolvem no seu psicológico, emocional, etc!!! Temos que ser fortes e não desanimar pq não é fácil...”; “Antes de julgar alguém ou uma cultura, procure conhecê-la."; "Yo creo que el Paraguayo que vive en la frontera tiene mucha influenza del Brasil y digamos que en el idioma no tiene dificultad ninguna, en la musica tambien pasan mucho tiempo escuchando sertanejo, funk y eso va creciendo cuando estudias en el país vecino. Y que tambien la educación es bien diferente y mucho mejor que a veces nos cuesta adaptarnos a su sistema."; "Estudar no Paraguai mudou a minha visão sobre o país. Muitos têm "preconceito" (inclusive eu tinha um pouco), e julgam ser ruim. Mas pelo contrário, tem uma ótima qualidade, um ótimo preço se comparar ao Brasil."

\section{Conclusão}

A análise dos dados coletados me permite inferir que o motivo preponderante de escolha da educação universitária em um outro país, nos estudantes entrevistados, foi o fator econômico, seja mediante a concessão de bolsa de estudo ou em razão de mensalidades menores no país vizinho. Destaco, neste tópico, a forte presença de brasileiros, na Tríplice Fronteira, que estudam Medicina no Paraguai, em razão do custo muito menor das mensalidades.

O interesse prévio no país vizinho se vinculava mais a fatores comerciais (compras) do que à busca por conhecimento da cultura do país limítrofe. 
A dificuldade do idioma, os hábitos alimentares distintos e a xenofobia se apresentavam como as principais barreiras imaginadas pelos indivíduos entrevistados em relação ao futuro país de destino educacional.

A partir do contato, o mesmo percentual de entrevistados (45\%) passou a apontar a boa receptividade que tiveram (amabilidade e hospitalidade) como os principais pontos positivos do país de destino.

A mesma mudança ocorreu na visualização do "outro", de um conceito negativo - da visão prévia e arquetípica - para o conceito positivo, após o efetivo contato.

As palavras não-receptivos, racistas, preguiçosos, desorganizados, arrogantes, xenofóbicos foram, em regra, substituídas por ricos culturalmente, calorosos, avançados, capazes e inteligentes.

No que se refere aos aspectos linguísticos, o aprendizado de um outro idioma se apresenta como um ganho colateral dos estudantes entrevistados. Noventa por cento deles se comunicam utilizando a língua estrangeira na universidade; oitenta por cento dos mesmos fazem uso de interjeições e expressões do idioma não-nativo no seu cotidiano.

Em relação aos aspectos culturais, sessenta por cento dos entrevistados acabaram por incorporar hábitos alimentares, musicais e de vestimenta do outro país, no seu cotidiano. Pude verificar nesta pesquisa que cruzar a fronteira, para estudar uma carreira universitária, não implica apenas na aquisição de conhecimento formal e técnico. Há significativa troca de experiências, com o compartilhamento de costumes e formas de comunicação. Também houve drástica mudança de concepção, para melhor, sobre o "outro", ou seja, acerca do país vizinho e das pessoas que o habitam.

\section{Referências}

APPADURAI, Arjun. Soberania sin territorialidade. Notas para una geografia pósnacional, 1997.

DAY, Kelly Cristina Nascimento. Fronteiras linguísticas e fronteiras políticas: relações linguísticas e socio-históricas na fronteira do brasil com a guiana francesa. Cadernos de Letras da UFF, v. 23, n. 47, $2013 . \quad$ Disponível em http://www.cadernosdeletras.uff.br/index.php/cadernosdeletras/article/view/320; acesso em $12 / 06 / 2018$.

DURHAN, Eunice. A dinâmica da cultura. Cosac \& Naify, 2004.

GEERTZ, Clifford. A interpretação das culturas. Rio de Janeiro: Guanabara Koogan, 1989. O saber local. Petrópolis, RJ: Vozes, 1997.

KUPER, Adam. Cultura, a visão dos antropólogos. Bauru, SP: EDUSC, 2002. 
MARTINEZ, Oscar. Border People: Life and Society in the US-Mexico Borderlands; Tucson, 1994.

MONTENEGRO, Silvia. La triple frontera entre Argentina, Brasil y Paraguay: globalización y construcción social del espacio. XXVI Congreso de la Asociación Latinoamericana de Sociología . Asociación Latinoamericana de Sociología, Guadalajara, 2007.

PASSI, Anssi. Boundaries as Social Processes: Territoriality in the World of Flows; disponível em: https://www.researchgate.net/publication/232860815_Boundaries_as_Social_Processes_Ter ritoriality_in_the_World_of_Flows ; acesso em 03/05/2018;

SEGATO, R. L. La Nación y sus otros. Buenos Aires: Prometeo, 2007.

SILVA, C. R.; GOBBI, B. C.; SIMÃO, A. A. O uso da análise de conteúdo como uma ferramenta para a pesquisa qualitativa: descrição e aplicação do método In: Organ. Rurais agroind. Lavras (MG), n. 1, v. 7, p. 70-81, 2005. Disponível em: http://ageconsearch.umn.edu/record/44035/files/revista_v7_n1_jan-abr_2005_6.pdf . Acesso em maio de 2018.

SILVA, Regina Coeli Machado. Reordenação de identidades de imigrantes árabes em Foz do Iguaçu. Trabalhos em Linguística Aplicada, v. 47, n. 2, p. 357-373, 2008.

UDESC. Metodologia Científica e da Pesquisa. Pesquisa científica: conceito e tipos Disponível em: http://www.joinville.udesc.br/portal/professores/cristala/materiais/Unidade3aPesquisaCientif ica.pdf . Acesso em maio de 2018. 